\title{
A Molecular Switch Based on a Biologically Important Redox Reaction
}

Ping Yan, Michael W. Holman, Paul Robustelli, Arindam Chowdhury, Fady I. Ishak and David M. Adams ${ }^{*}$

Department of Chemistry, Columbia University, New York, New York 10027

Supporting Information

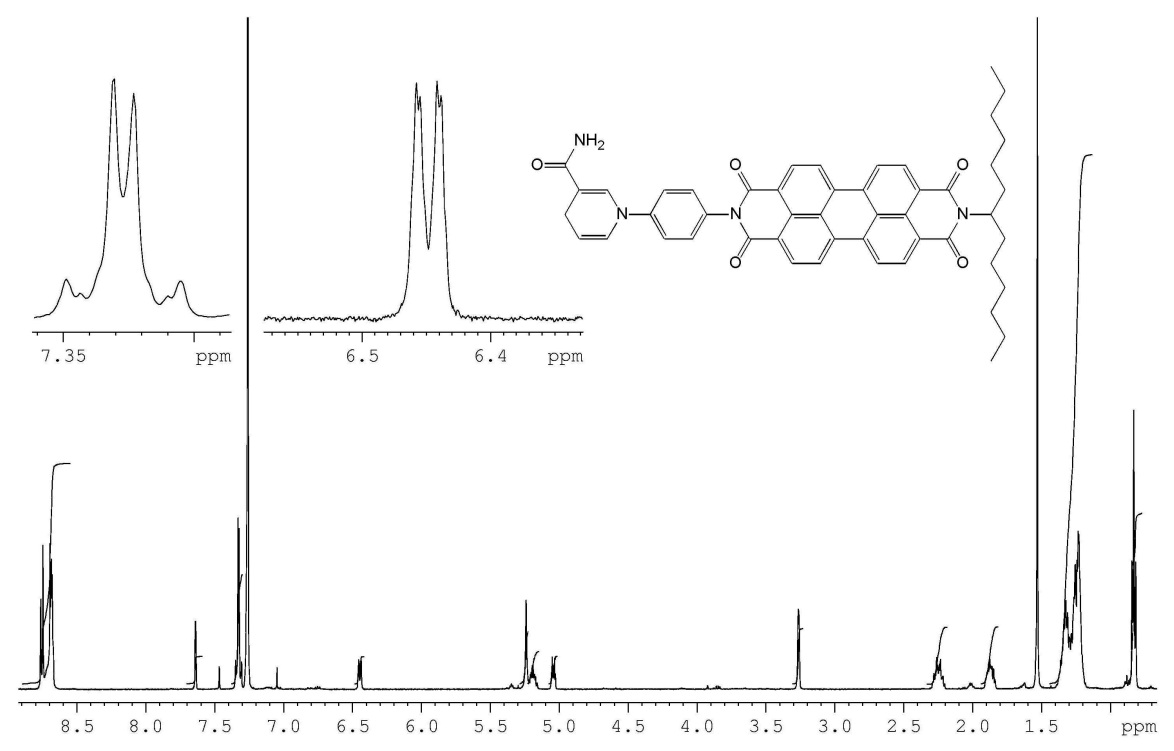

Figure S1. ${ }^{1} \mathrm{H}$ NMR $\left(500 \mathrm{MHz}, \mathrm{CDCl}_{3}\right)$ of $\mathbf{3}$. 


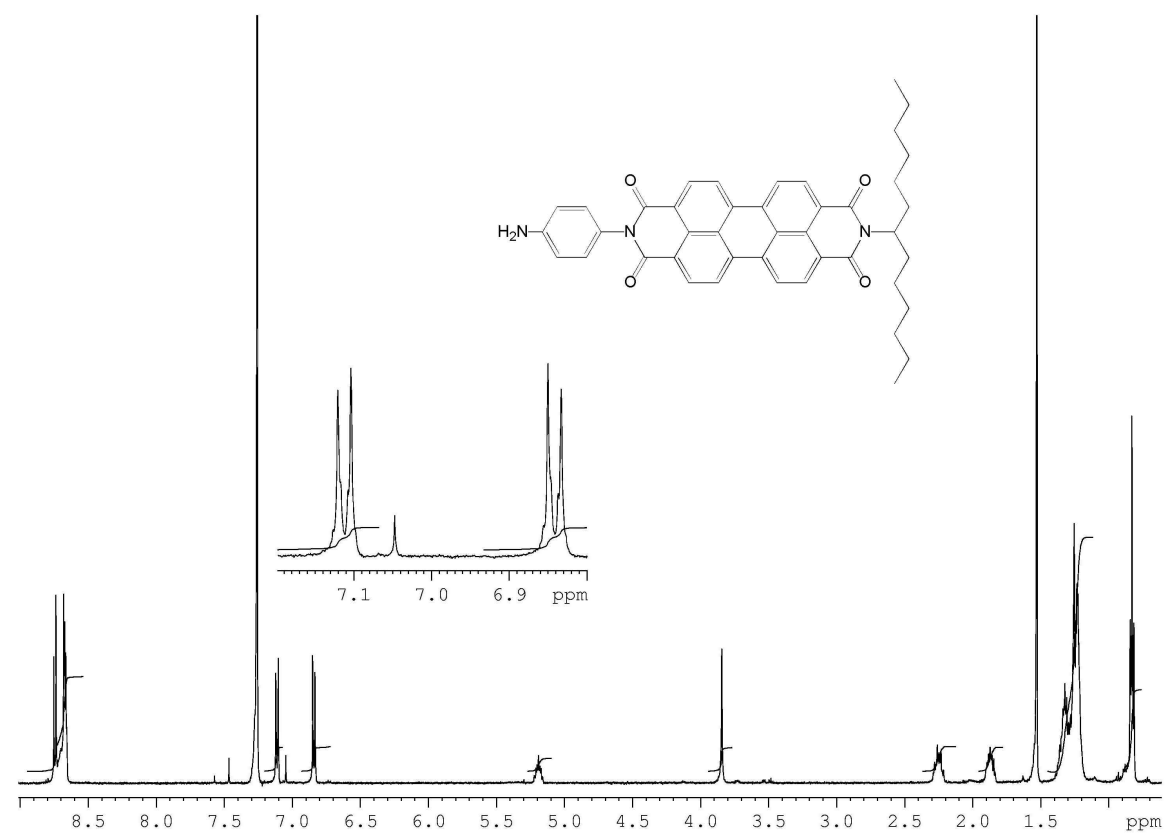

Figure S2. ${ }^{1} \mathrm{H}$ NMR $\left(500 \mathrm{MHz}, \mathrm{CDCl}_{3}\right)$ of 4.

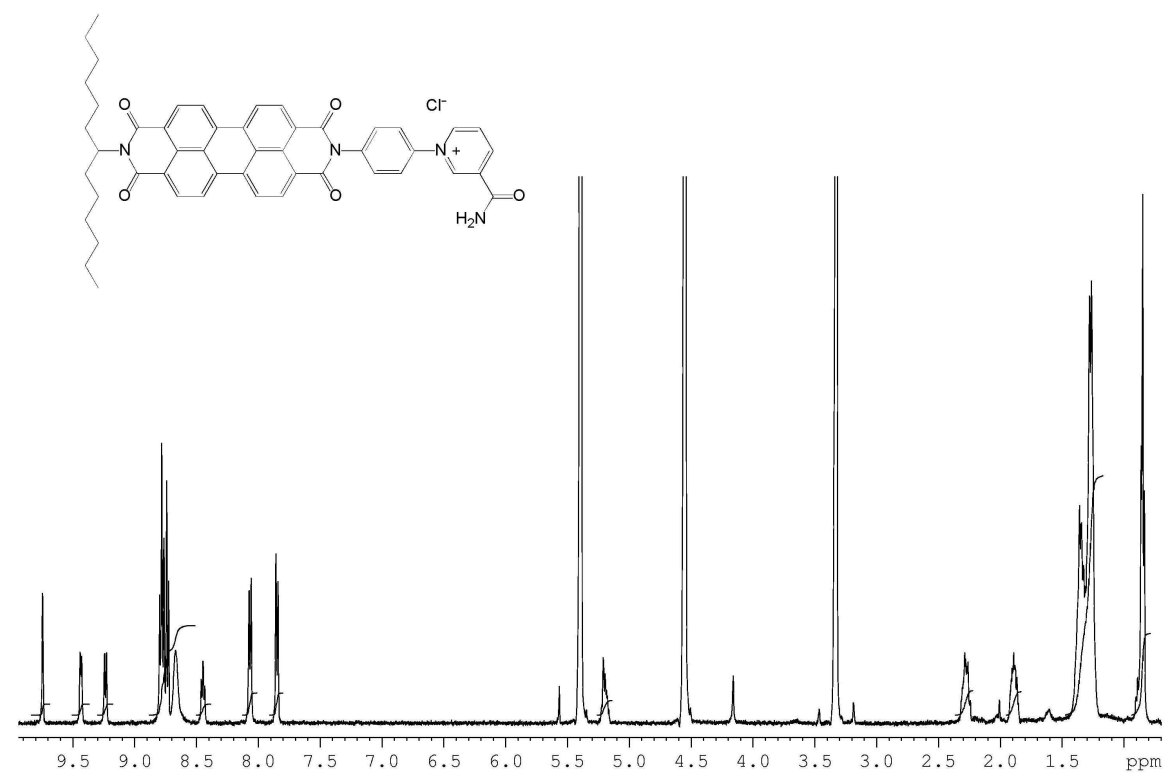

Figure S3. ${ }^{1} \mathrm{H}$ NMR $\left(500 \mathrm{MHz}, 1: 1 \mathrm{CD}_{2} \mathrm{Cl}_{2} / \mathrm{CD}_{3} \mathrm{OD}\right)$ of 6 . 


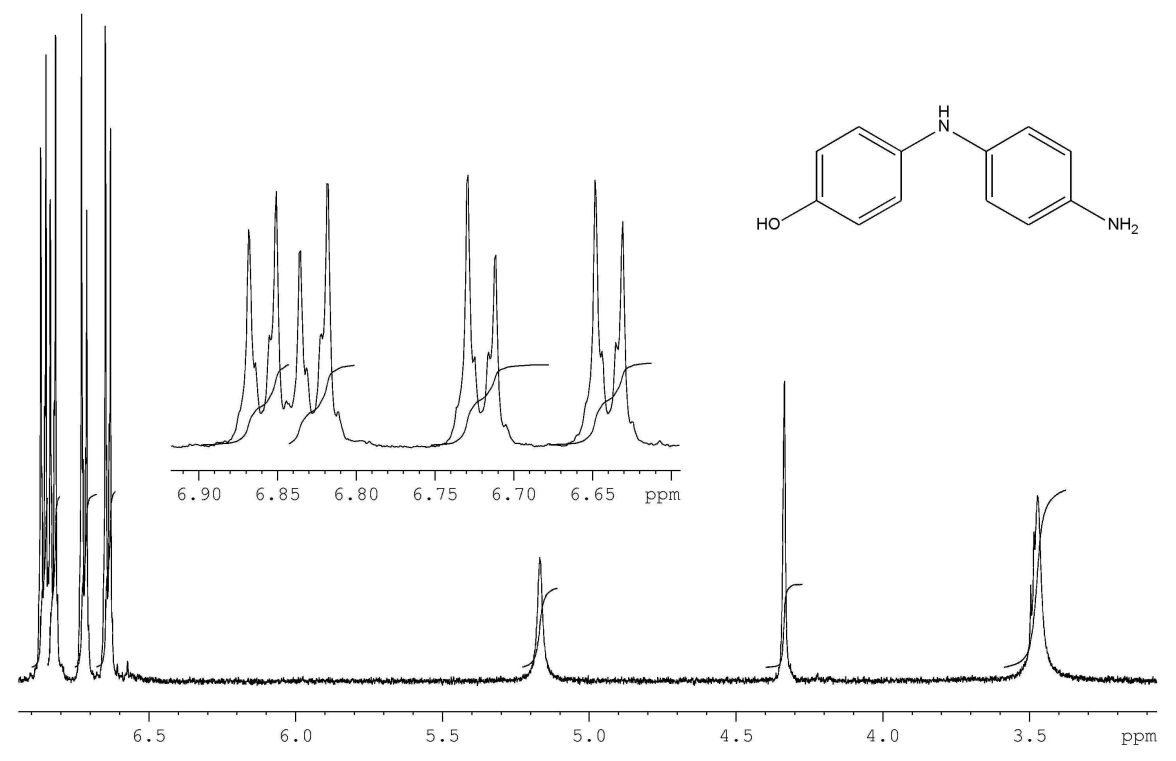

Figure S4. ${ }^{1} \mathrm{H}$ NMR $\left(500 \mathrm{MHz}, \mathrm{CDCl}_{3}\right)$ of 8 .

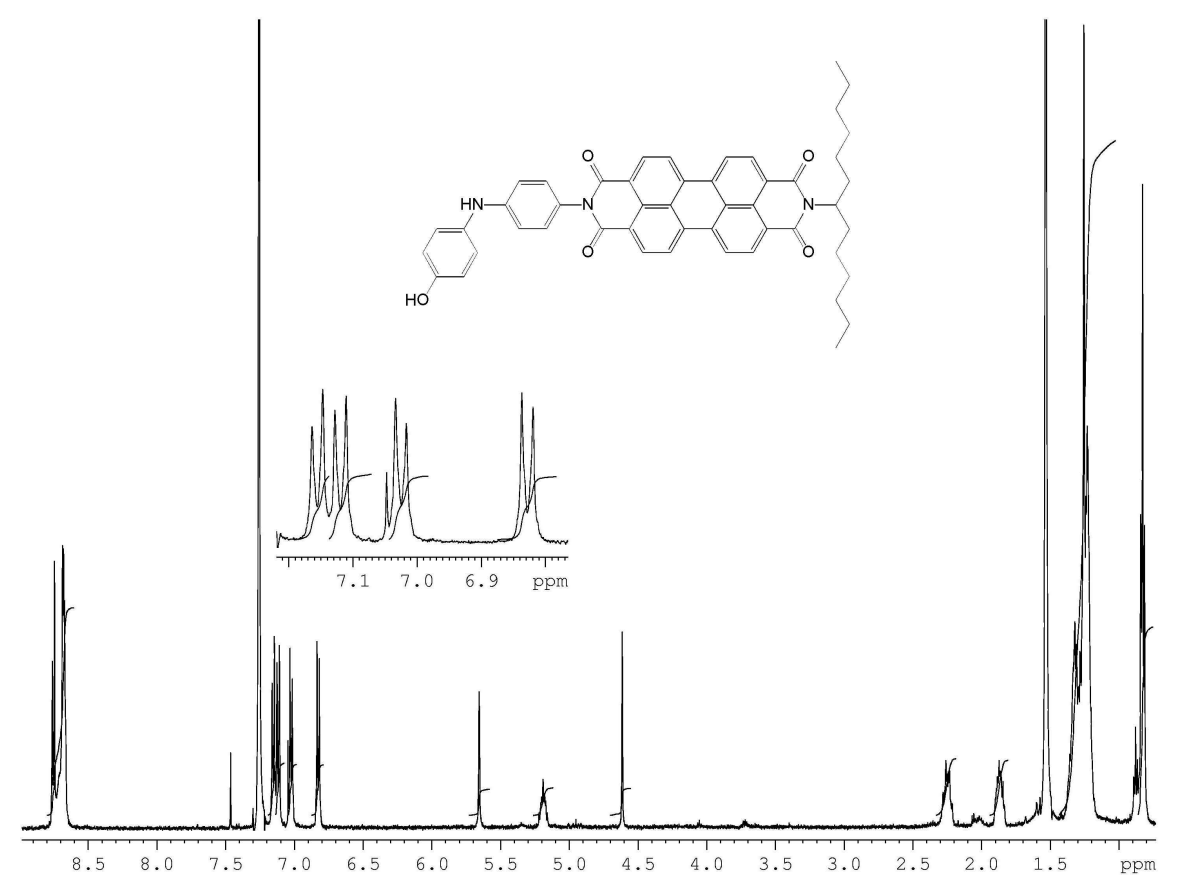

Figure S5. ${ }^{1} \mathrm{H}$ NMR $\left(500 \mathrm{MHz}, \mathrm{CDCl}_{3}\right)$ of 9. 


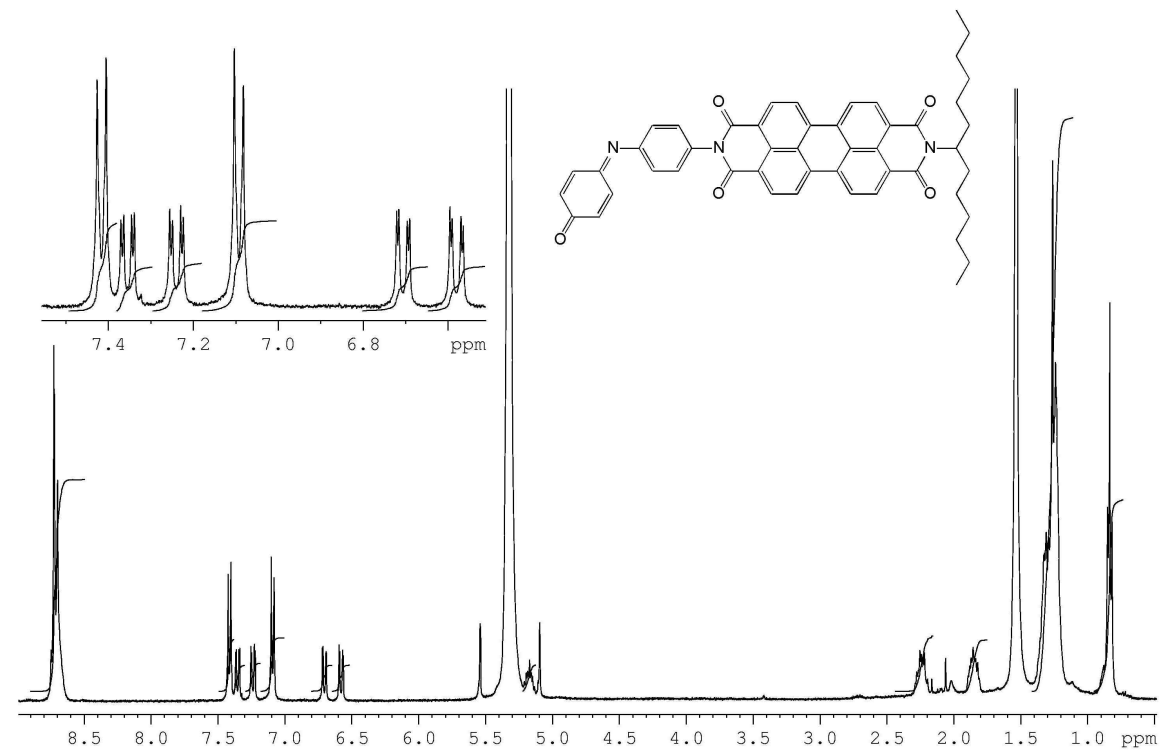

Figure S6. ${ }^{1} \mathrm{H}$ NMR (400 MHz, $\left.\mathrm{CD}_{2} \mathrm{Cl}_{2}\right)$ of $\mathbf{1 0}$. 